http://dx.doi.org/10.11646/zoosymposia.15.1.11

http://zoobank.org/urn:Isid:zoobank.org:pub:D613A9CC-C880-4194-941F-A81AB570A345

\title{
First evidence of autofluorescence of a cell mass in developing temnopleurid sea urchins
}

\author{
CHISATO KITAZAWA ${ }^{1,2} \&$ AKIRA YAMANAKA ${ }^{3,4}$ \\ ${ }^{1}$ Biological Institute, Faculty of Education, Yamaguchi University, Yoshida 1677-1, Yamaguchi 753-8513, Japan \\ ${ }^{2}$ Social System Analysis, The Graduate School of East Asian Studies, Yamaguchi University, Yoshida 1677-1, Yamaguchi 753-8514, \\ Japan \\ ${ }^{3}$ Department of Biology \& Chemistry, Faculty of Science, Yamaguchi University, Yoshida 1677-1, Yamaguchi 753-8512, Japan \\ ${ }^{4}$ Department of Biology, Graduate School of Science and Technology for Innovation, Yamaguchi University, Yoshida 1677-1, \\ Yamaguchi 753-8512, Japan \\ ${ }^{1,2}$ Corresponding author, E-mail: chisak@yamaguchi-u.ac.jp
}

\begin{abstract}
The pigment cells of some sea urchin embryos emanate autofluorescence in response to light irradiation. However, it is unclear if this feature is maintained throughout larval development. In the present study we observed embryos and larvae of the temnopleurid sea urchins Temnopleurus hardwickii, T. reevesii, T. toreumaticus and Mespilia globulus exposed to light irradiation, and compared our findings with those of a strongylocentroid, Hemicentrotus pulcherrimus. After exposure to ultraviolet irradiation for a few minutes, there was a strong signal from the temnopleurid sea urchins. The signal was detected from a cell mass that is part of the adult (juvenile) rudiment, formed during development of the prism to the two-armed larval stage and not from pigment cells. This signal was observed in both live and formalin-fixed specimens. Fluorescence was also detected from the digestive organs, coelomic pouches, the ciliary band on the oral hood, from some yellowish-green cells and ectodermal cells, although there were some differences among species. In live H. pulcherrimus larvae, the amniotic cavity that is part of the adult rudiment emanated autofluorescence in response to ultraviolet irradiation. These results indicate that the autofluorescence observed in the cell mass of temnopleurid sea urchins is caused by a different mechanism than previously described. This feature may be a useful marker to trace development of the cell mass.
\end{abstract}

Key words: Autofluorescence, sea urchin larvae, temnopleurids, cell mass

\section{Introduction}

Many marine animals emanate fluorescence produced in different ways. Bioluminescence generated by a luciferin-luciferase reaction has been used for intraspecific communication and defense against predation in adult echinoderms except echinoids (Herring 1974; Mallefet 1999; Jones \& Mallefet 2013). Other marine animals use the green-fluorescent protein (GFP) to produce photoluminescence (Morise et al. 1974; Shimomura 1979).

In echinoderms, ophioplutei emanate fluorescence from the tip of the larval arms when irradiated with ultraviolet (UV) light (Kitazawa et al. 2014a). In some echinoids, including Hemicentrotus pulcherrimus and Scaphechinus mirabilis, the presumptive pigment cells in formalin-fixed gastrulae emanate autofluorescence when irradiated with UV and green light (Kominami et al. 2001). The pigment cells are the early specified group in secondary mesenchyme cells (SMCs) and accumulate pigment granules (Sweet et al. 2002; Ohguro et al. 2011; Materna \& Davidson 2012). When the (presumptive) pigment cells are fixed and then irradiated with UV, they break down their granules containing carotenoids and naphthoquinone (Kominami et al. 2001). 
In the pigment cells of the early larval stages of the echinoids, Clypeaster japonicus, H. pulcherrimus, Heliocidaris crassispina and Pseudocentrotus depressus, red granules broke up with irradiation from blue light and then released green fluorescent substance(s) into the cytoplasm (Nakamura et al. 2001). The strength and patterns of autofluorescence in the pigment cells of early larval stages differ among different echinoid species (Kominami et al. 2001; Nakamura et al. 2001). However, it is not known if late-stage larvae that obtain pigment cells until metamorphosis, emanate autofluorescence when irradiated with light.

Compared with model echinoid species such as Strongylocentrotus purpuratus and H. pulcherrimus, sea urchins in the family Temnopleuridae have many unique developmental features, including wrinkled egg formation after fertilization (Kitazawa et al. 2009, 2010), wrinkled blastula formation (Kitazawa et al. 2009, 2010, 2016), variation in gastrulation among species (Takata \& Kominami 2004; Kitazawa et al. 2016), double primary pore canal formation (Hara et al. 2003; Kitazawa et al. 2012, 2014b), and formation of the early adult rudiment from a cell mass (CM) (Fukushi 1959; Ubisch 1959; Kitazawa et al. 2012, 2014b). Studies on the developmental mechanisms of temnopleurids are relatively new, so it is not known if the embryos and larvae emanate autofluorescence with light irradiation. Also, Fukushi (1959) observed brown pigment granules in CM of larvae of T. hardwickii (Fukushi 1959). If the CM emanates autofluorescence with light irradiation, it will be helpful to analyze the CM development.

We observed the embryos and larvae of four temnopleurid sea urchin species under light irradiation and compared our findings with those of the strongylocentroid urchin, H. pulcherrimus.

\section{Materials and Methods}

Adult sea urchins were collected from the Inland Sea at Setonai, Yamaguchi Prefecture, Japan. A small amount of $0.5 \mathrm{M} \mathrm{KCl}$ solution was injected into the body cavity of the urchins to induce spawning. After being washed several times, the eggs were fertilized and cultured in plastic dishes (diameter $10 \mathrm{~cm}$ ) containing artificial sea water (ASW) (TetraMarin ${ }^{\circledR}$ Salt Pro, Tetra, Melle, Germany). Temnopleurus hardwickii, T. reevesii, T. toreumaticus and Mespilia globulus were cultured at $24^{\circ} \mathrm{C}$ and Hemicentrotus pulcherrimus was cultured at $18^{\circ} \mathrm{C}$. Larvae were reared until they developed into the four-armed stage.

Approximately 50 larvae of each species were transferred to $50 \mathrm{ml}$ plastic tubes filled with ASW. A few drops of ASW containing the diatom Chaetoceros gracilis were added to each plastic tube as a food source for the larvae, according to the methods of Wray et al. (2004) and Kitazawa et al. (2012), with some modifications. Some larvae were fixed in $4 \%$ formalin in ASW for $45 \mathrm{~min}$ at room temperature or in magnesium-free 10\% formalin in ASW for 20 min using the modified methods of Kominami et al. (2001).

Fixed specimens were washed with distilled water (DW) several times. Live and fixed specimens were then observed and photographed under a fluorescence microscope (ECLIPSE E200, E2-FL, Nikon, Tokyo, Japan) equipped with a digital camera (DS-Fil, Nikon). After a few minutes irradiation with each light, the fluorescence signals of the specimens were detected through the barrier filter (DAPI filter for ultraviolet (UV) irradiation; EX 340-380 nm, BA 435-485 nm; B-2A filter for blue light irradiation; EX 450-490 nm, BA 520 $\mathrm{nm}$, Nikon) according to Kominami et al. (2001).

Some alive larvae were kept in a micro tube and heated to $85^{\circ} \mathrm{C}$ for $20 \mathrm{~min}$ or $100^{\circ} \mathrm{C}$ for $10 \mathrm{~min}$ in a thermoelectric cooling unit (CTU-Neo, Taitec, Aichi, Japan) before being observed using the fluorescence microscope.

\section{Results}

It is known that fix and light irradiation are necessary to autofluorescence in the (presumptive) pigment cells during the gastrula to early larval stages (Kominami et al. 2001). On the other hand, Nakamura et al. (2001) detected autofluorescence by light irradiation on living early-staged larvae of some species. As it is considered species- and stage-specific differences, at first, we observed the effects of light irradiation on formalin-fixed Temnopleurus hardwickii embryos. All fixed late-gastrula embryos emanated autofluorescence from secondary mesenchyme cells (SMCs) when irradiated with ultraviolet (UV) light. Some embryos emanated autofluorescence from part of the left side of the embryonic body $(18.8 \%, n=16)$. No signals were detected using blue light irradiation $(n=7)$ (data not shown). 

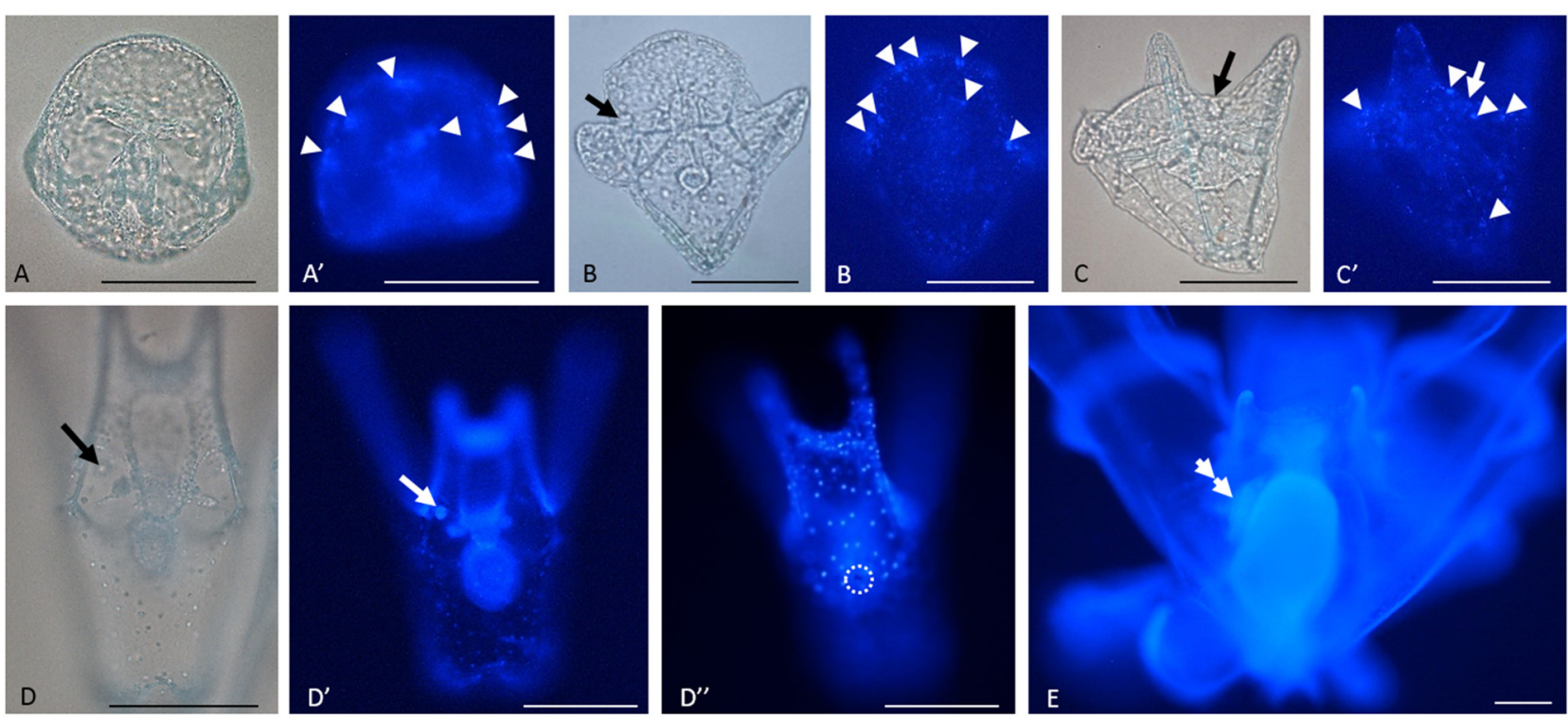

FIGURE 1. Autofluorescence of fixed embryos and larvae of Temnopleurus hardwickii. (A-D) are light field and ( $\mathrm{A}^{\prime}-\mathrm{D}^{\prime}, \mathrm{D}^{\prime \prime}$ and E) are dark field views using ultraviolet irradiation. A. Embryo $21.5 \mathrm{~h}$ after fertilization (dorso-ventral view). Some secondary mesenchyme cells (SMCs) emanated autofluorescence. At this stage, a cell mass (CM) did not formed yet. B, C. Two-armed larvae $27 \mathrm{~h}$ after fertilization (B; dorsal view, $\mathrm{C}$; diagonal ventral view). Some SMCs and some cells in CM emanated weak autofluorescence. D. Larva 2 days after fertilization (dorsal view). The CM emitted autofluorescence $\left(\mathrm{D}^{\prime}\right)$. The oral region of the ciliary band, digestive organs and coelomic pouches fluoresced. Pigment granule-like substance on the ectodermal cells also emanated autofluorescence ( $\left.\mathrm{D}^{\prime \prime}\right)$. However, pigment cells did not emanate (in a white circle). E. Larva 43 days after fertilization (dorsal view). The adult rudiment weakly emanated autofluorescence. Arrowheads: SMCs. Arrows: CM. Double arrows: Adult rudiment. Scale bars: $100 \mu \mathrm{m}$.

At the prism stage, fixed T. hardwickii embryos continued to emanate autofluorescence from SMCs (Fig. $1 \mathrm{~A}$ and $\mathrm{A}^{\prime}$ ). There was a positive response to the irradiation from some cells located on the left side of the embryos, the presumptive position of a cell mass $(\mathrm{CM})(82.4 \%, n=17)$. Two-armed pluteus larvae continued to emanate autofluorescence from the SMCs with positive signals in response to UV irradiation (Fig. 1B and C) and weak signals in response to blue light irradiation (data not shown because it was very difficult to recognize signals in photographs). The pattern of autofluorescence changed during larval growth (Fig. 1D). The pigment cells did not emanate autofluorescence; however, cells located in the CM produced a strong signal (Fig. 1D'). The strong positive signals were observed as a single granule in each cell of the CM $(100 \%$, $n=4$ ). Blue light irradiation also resulted in a weak signal from the CM (data not shown because it was very difficult to recognize signals in photographs). When the CM increased in diameter, the signal from inside the $\mathrm{CM}$ was strong in response to both UV and blue light irradiation $(100 \%, n=5$ or 6 , respectively). Formalinfixed larvae also showed autofluorescence from the digestive organs, coelomic pouches, ciliary band at the oral hood and ectodermal cells, in addition to the CM (Fig. 1 $\mathrm{D}^{\prime}$ and $\left.\mathrm{D}^{\prime \prime}\right)(100 \%, n=31)$. During the six- to eight-armed larval stages, fluorescence signals were also detected from the yellowish-green cells in the arms and epaulet. As larvae neared metamorphosis, the CM formed an adult rudiment. Autofluorescence in the adult rudiment decreased at this stage of development (Fig. 1E).

Live larvae strongly emanated strong autofluorescence from the CM when irradiated with UV (Fig. 2AD), but no autofluorescence emanated from the pigment cells of early-stage live larvae $(100 \%$ at 3 days after fertilization, $n=26$ ). Fluorescent signals were also detected from the digestive organs, but not from ectodermal cells or the ciliary band of live larvae. Although blue light irradiation did not cause fluorescence before $\mathrm{CM}$ formation $(n=6)$, formation of the $\mathrm{CM}$ resulted in autofluorescence (Fig. 2E and $\mathrm{E}^{\prime}$ ). When live larvae were irradiated with UV a second time after a few days later, they emanated fluorescence from the same regions as described above. 

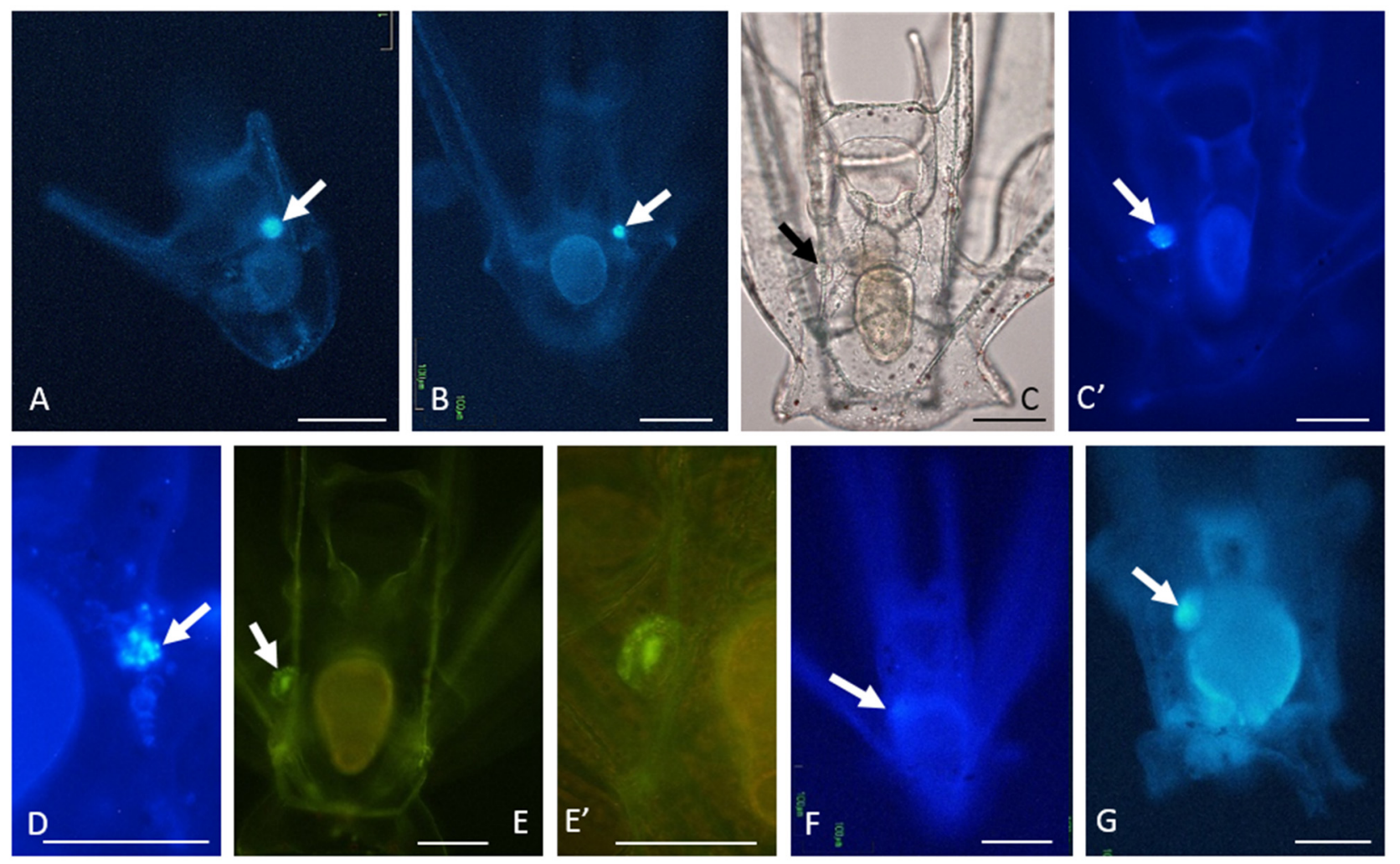

FIGURE 2. Autofluorescence of live Temnopleurus hardwickii larvae. (C) is a light field and (A, B, C', D, F and G) are dark field views using ultraviolet. (E and $\mathrm{E}^{\prime}$ ) are dark field views using blue light irradiation. A-D. Larvae 3 days, 23 days and 61 days after fertilization (A; diagonal ventral view, B and D; ventral views, C; dorsal view). The cell mass (CM) and stomach emanated autofluorescence (A-C). Each cell in the CM emanated autofluorescence (D). E. Larva 61 days after fertilization. Under blue light irradiation, the inside of the $\mathrm{CM}$ emanated autofluorescence. F and $\mathrm{G}$. Larvae 31 days after fertilization heated to $85^{\circ} \mathrm{C}$ for $20 \mathrm{~min}(\mathrm{~F})$ or to $100^{\circ} \mathrm{C}$ for $10 \mathrm{~min}(\mathrm{G})$. Autofluorescence emanated from the $\mathrm{CM}$ and the digestive organs. Arrows: CM. Scale bars: $100 \mu \mathrm{m}$.

The CM of six-to-eight-armed T. hardwickii larvae that were heated to $85^{\circ} \mathrm{C}$ for $20 \mathrm{~min}$, emanated autofluorescence when irradiated with UV light $(90.9 \%, n=11)(\mathrm{Fig} .2 \mathrm{~F})$. Larvae that were heated to $100^{\circ} \mathrm{C}$ for $10 \mathrm{~min}$ also emanated autofluorescence ( $88.9 \%$ of larvae) from the $\mathrm{CM}$ and the stomach in response to UV irradiation $(n=18)$ (Fig. $2 \mathrm{G})$. However, the ciliary band and ectodermal cells of these larvae did not emanate autofluorescence.

Formalin-fixed $T$. reevesii embryos emanated weak autofluorescence from presumptive pigment cells, prior to the prism stage ( $100 \%$ at $18 \mathrm{~h}$ after fertilization, $n=29)$ (Fig. 3A and B). Following the prism stage, larvae emanated autofluorescence from the CM, digestive organs, ciliary band on the oral hood and ectodermal cells, but not from the pigment cells $(100 \%, n=9)$ (Fig. 3C-E). Live eight-armed T. reevesii larvae also emanated fluorescence from the surface of the tube feet in the adult rudiment (Fig. 3F and $\mathrm{F}^{\prime}$ ) and from the yellowish-green cells $(100 \%, n=7)$ (Fig. 3F" and $\left.\mathrm{F}^{\prime \prime \prime}\right)$. Formalin-fixed T. toreumaticus two-armed larvae emanated autofluorescence from the presumptive pigment cells (Fig. 3G) and then from the CM. Additionally, the coelomic pouches, digestive organs and the ciliary band at the oral hood also radiated fluorescence $(100 \%, n=14)$. At the six-armed larval stage, a signal was detected from the CM in fixed larvae (Fig. $3 \mathrm{H})$ and weak fluorescence was detected in eight-armed larvae from the tip of the tube feet in the adult rudiment and under the epaulet. In live larvae, fluorescent signals were detected from the $\mathrm{CM}$ and from the surface of the adult rudiment, stomach and from some of the yellowish-green cells $(100 \%, n=15)$ (Fig. 3I, J and $\mathrm{J}^{\prime}$ ). The small process that developed from the anterior part of the $\mathrm{CM}$ also produced a fluorescent signal in response to UV light. The fluorescence patterns in the larval stage of M. globulus were similar to those described for the other temnopleurid species. In fixed specimens, the presumptive pigment cells produced a fluorescent signal during the gastrula-to-prism stages (Fig. 3K). Two-armed and four-armed fixed M. globulus larvae emitted positive signals from the $\mathrm{CM}$, the ciliary band on the oral hood, the digestive organs, coelomic 
pouches and the ectodermal cells $(100 \%, n=15)\left(\right.$ Fig. $3 \mathrm{~L}$ and $\left.\mathrm{L}^{\prime}\right)$. Live eight-armed larvae near metamorphosis gave fluorescent signals from the surface of the tube feet in the adult rudiment, the epaulet and from some of the yellowish-green cells $(83.3 \%$ at 6 days after fertilization, $n=12)$ (Fig. 3M). These results indicate that the patterns of autofluorescence in response to UV irradiation are conserved, but the strength of the response differs among temnopleurid sea urchins.

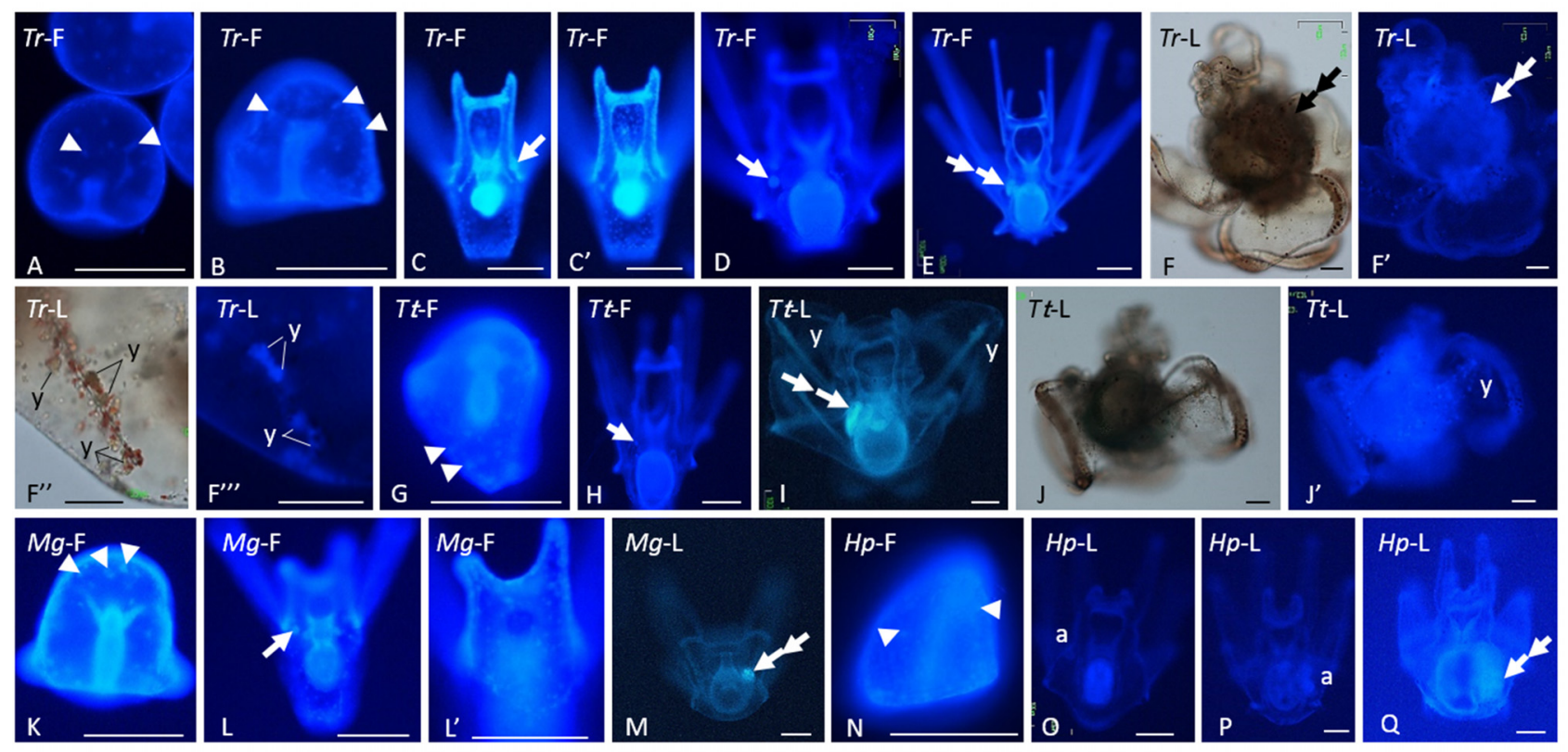

FIGURE 3. Autofluorescence of embryos and larvae of other temnopleurid species. $\left(F, F^{\prime \prime}\right.$ and $\left.J\right)$ are light field and (A-E, $F^{\prime}$, $\mathrm{F}^{\prime \prime \prime}, \mathrm{G}-\mathrm{I}, \mathrm{J}^{\prime}, \mathrm{K}-\mathrm{Q}$ ) are dark field views of specimens exposed to ultraviolet irradiation. Labels on the photographs mean species name (Tr for Temnopleurus reevesii; Tt for T. toreumaticus; $M g$ for M. globulus; Hp for Hemicentrotus pulcherrimus) and categories of fixed (F) or live specimens (L). A-F. T. reevesii. At $18 \mathrm{~h}$ after fertilization (A), embryos weakly emanated autofluorescence at secondary mesenchyme cells (SMCs) until the prism stage (B, 19.5 h after fertilization) (A and B: lateral views). Four-armed pluteus larvae (7 days after fertilization) showed autofluorescence from the cell mass (CM), the digestive organs, the ciliary band on the oral hood, the coelomic pouches $(C)$ and the pigment granules on the ectoderm $\left(\mathrm{C}^{\prime}\right)(\mathrm{ventral}$ views). Six-to-eight-armed larvae (14 days after fertilization) continued to emit autofluorescence at the CM (D and E: dorsal views). Near metamorphosis $(F)$, the adult rudiment emanated weak autofluorescence $\left(F^{\prime}\right)$ and the yellowish-green cells $(y)$ in the larval arms emanated autofluorescence, but pigment cells showed no autofluoresence ( $\mathrm{F}^{\prime \prime}$ and $\left.\mathrm{F}^{\prime \prime \prime}\right)$ (ventral view). G-J. T. toreumaticus. At the 2-armed larval stage (G, $25 \mathrm{~h}$ after fertilization; dorso-ventral view), SMCs emanated autofluorescence and the CM started to emit autofluorescence. During the larval stages (H; dorsal view), the CM continued to emit signals until adult rudiment formation (I, 15 days after fertilization; dorsal view). Near metamorphosis (J), the signals became weak, although some yellowish-green cells emanated fluorescence $\left(\mathrm{J}^{\prime}\right)$ (lateral view). K-M. M. globulus. Embryos (24 h after fertilization) emanated autofluorescence at SMCs (K; dorso-ventral view) and 1 day later the CM, coelomic pouches, some pigment granules of the ectoderm and the ciliary band on the oral hood produced an autofluorescent signal ( $\mathrm{L}$ and L'; dorsal views). The CM in live larvae also fluoresced in response to UV (M, 6 days after fertilization; ventral view). N-Q. $H$. pulcherrimus. At 1.5 days after fertilization (N, lateral view), some SMCs emanated weak autofluorescence and then at the sixto-eight-armed larval stages the amniotic cavity (a) (O; dorsal view, P; ventral view; 11 days after fertilization) and adult rudiment emitted autofluorescence $(\mathrm{Q}, 21$ days after fertilization, ventral view). Arrowheads: SMCs. Arrows: CM. Double arrows: adult rudiment. Scale bars: $100 \mu \mathrm{m}$.

In the strongylocentroid $H$. pulcherrimus, positive signals were identified from the (presumptive) pigment cells only in fixed specimens during the gastrula to four-armed larval stages $(68.1 \%$ at the two- to four-armed larval stages, $n=69$ ) (Fig. $3 \mathrm{~N}$ ). At the eight-armed stage, the fixed larvae emanated autofluorescence under the epaulet and at the tip of the tube feet in the adult rudiment in response to UV irradiation. In contrast, live six-to-eight-armed larvae radiated autofluorescence from inside the amniotic cavity (or the tip of the tube feet in adult rudiment) and the hydrocoel (Fig. 3O-Q). When larvae were heated to $85^{\circ} \mathrm{C}$ for 20 min, weak autofluorescence still emanated from the ciliary band and the tube feet in two of three specimens. 


\section{Discussion}

This study showed that embryos and late-stage larvae emanate autofluorescence in response to UV irradiation. The embryos of temnopleurid sea urchins had an autofluorescence pattern similar to other sea urchin species (Nakamura et al. 2001; Takata \& Kominami 2011). Embryos emanated autofluorescence at the presumptive pigment cells, although signal strength differed among species (Nakamura et al. 2001). This may be a common trait among sea urchins. However, after pigment differentiation and larval development, the pigment cells of temnopleurids and H. pulcherrimus no longer fluoresced (Figs. 1-3). Instead, a cell mass (CM) started to strongly emanate autofluorescence. The stomach, coelomic pouches, ciliary band and ectodermal cells of early-stage larvae and some of the yellowish-green cells in later larval stages also emanated autofluorescence. These new observations are unique features of temnopleurid sea urchins.

The brown pigment granules that were described from the ectoderm of T. hardwickii (Fukushi 1959) emanate autofluorescence with UV irradiation. A CM is formed by cells on the left side of the larval ectoderm, and the brown pigment granules located on the outer cell surface migrated into the center of the CM (Fukushi 1959). In the present study, we observed a strong signal from the center of the CM in $T$. hardwickii larvae (Fig. 2D and E). This suggests that the brown pigment granules located in the CM may cause the autofluorescent response to UV irradiation. In the present study, we observed autofluorescence in the amniotic cavity and on the adult rudiment of $H$. pulcherrimus larvae (Fig. 3O-Q). Osanai (1969) found that unfertilized eggs of T. hardwickii and H. pulcherrimus contained brown pigment granules that remained around the outer edge of the egg after fertilization. This indicates that the localization of pigment granules is highly conserved among species, and is in contrast to differences of adult rudiment formation, CM and the amniotic cavity.

We observed differences in the parts of larvae that showed autofluorescence between fixed and live specimens. In live C. japonicus larvae, blue light $(450-490 \mathrm{~nm})$ caused the release of green fluorescent substance(s) from pigment cells into the cytoplasm in different parts of the body and the tips of the post-oral arms (Nakamura et al. 2001). Kominami et al. (2001) found that carotenoids and naphthoquinones contained in the larval pigment cells of fixed larvae produce fluorescence following green light or UV excitation, but that pigment cells in living specimens did not emanate fluorescence. In the present study, we did not observe the release of fluorescence substances from pigment cells. This indicates that temnopleurid larvae emanate autofluorescence using different mechanisms, or that the concentration of the formalin used to fix these species was not high enough to produce this effect. In $H$. pulcherrimus, the autofluorescence of some pigment cells is reduced during development when exposed to UV excitation, but all pigment cells fluoresced in response to excitation with green light (Kominami et al. 2001). It has been suggested that carotenoids and naphthoquinones are released from the pigment granules through the fixation process and then fluorescent ones are released from the carotenoid- or naphthoquinone-protein complexes (Kominami et al. 2001). Our observations suggest that the autofluorescence of ectodermal structures including the CM in temnopleurid larvae may be caused by substances that differ from those of pigment cells. The green fluorescent protein (GFP) is a relatively stable molecule (Bokman \& Ward 1981), but the fluorescence level of the GFP in the hydrozoan Aequorea sp. decreased at temperatures over $65^{\circ} \mathrm{C}$. In the present study, there was more autofluorescence emitted from T. hardwickii larvae that had been exposed to $100^{\circ} \mathrm{C}$ was greater than that of $H$. pulcherrimus larvae that had not been exposed to high temperatures. It is possible that $T$. hardwickii contains a specific substance that causes autofluorescence. Autofluorescence may also be caused by different substances in the pigment cells of larvae during the early developmental stage. Our results indicate that the CM emanates autofluorescence through different mechanisms, but the reason for the autofluorescence is not clear. Although the CM was analyzed using a morphological approach, the trait of autofluorescence will help as a marker to trace the development of the CM.

However, it is still not clear why the larvae emanate autofluorescence. This trait might cause to hide in wave in the sea by light reflection from predators. The future research will be clear this larval strategy.

\section{Acknowledgements}

We thank the department of fishery in Yamaguchi Prefecture and Yamaguchi Fisheries Cooperative Association for permission of collecting sea urchins. 


\section{References}

Bokman, S.H. \& Ward, W.W. (1981) Renaturation of Aequorea green-fluorescent protein. Biochemical Biophysical Research Communications, 101, 1372-1380. https://doi.org/10.1016/0006-291X(81)91599-0

Fukushi, T. (1959) On the cell mass observed on the left side of the pluteus of the sea urchin, Temnopleurus hardwickii. The bulletin of the Marine Biological Station of Asamushi, 9, 133-135.

Hara, Y., Kuraishi, R., Uemura, I. \& Katow, H. (2003) Asymmetric formation and possible function of the primary pore canal in plutei of Temnopleurus hardwicki. Development, Growth \& Differentiation, 45, 295-308. https://doi.org/10.1046/j.1440-169X.2003.00697.x

Herring, P.J. (1974) New observations on the bioluminescence of echinoderms. Journal of Zoology, London, 172, $401-418$. https://doi.org/10.1111/j.1469-7998.1974.tb04116.x

Jones, A. \& Mallefet, J. (2013) Why do brittle stars emit light? Behavioural and evolutionary approaches of bioluminescence. Cahiers de Biologie Marine, 54, 729-734.

Kitazawa, C., Nishimura, H., Yamaguchi, T., Nakano, M. \& Yamanaka, A. (2009) Novel morphological traits in the early developmental stages of Temnopleurus toreumaticus. The Biological Bulletin, 217, 215-221. https://doi.org/10.1086/BBLv217n3p215

Kitazawa, C., Tsuchihashi, Y., Egusa, Y., Genda, T. \& Yamanaka, A. (2010) Morphogenesis during early development in four Temnopleuride sea urchins. Information, 13, 1075-1089.

Kitazawa, C., Kobayashi, C., Kasahara, M., Takuwa, Y. \& Yamanaka, A. (2012) Morphogenesis of adult traits during the early development of Mespilia globulus Linnaeus, 1758 (Echinodermata: Echinoidea). Zoological Studies, 51, 1481-1489.

Kitazawa, C., Akahoshi, S., Sohara, S., Noh, J.T., Tajika, A., Yamanaka, A. \& Komatsu, M. (2014a) Development of the brittle star Ophiothrix exigua Lyman, 1874 a species that bypasses early unique and typical planktotrophic ophiopluteus stages. Zoomorphology. [Published Online] https://doi.org/10.1007/s00435-014-0233-8

Kitazawa, C., Sakaguchi, C., Nishimura, H., Kobayashi, C., Baba, T. \& Yamanaka, A. (2014b) Development of the sea urchins Temnopleurus toreumaticus Leske, 1778 and Temnopleurus reevesii Gray, 1855 (Camarodonta: Temnopleuridae). Zoological Studies, 53, 3. https://doi.org/10.1186/1810-522X-53-3

Kitazawa, C., Fujii, T., Egusa, Y., Komatsu, M. \& Yamanaka, A. (2016) Morphological diversity of blastula formation and gastrulation in temnopleurid sea urchins. Biology Open, 5, 1555-1566. https://doi.org/10.1242/bio.019018

Kominami, T., Takata, H. \& Takeichi, M. (2001) Behavior of pigment cells in gastrula-stage embryos of Hemicentrotus pulcherrimus and Schaphechinus mirabilis. Development, Growth \& Differentiation, 43, 699-707. https://doi.org/10.1046/j.1440-169X.2001.00605.X

Mallefet, J. (1999) Physiology of bioluminescence in echinoderms. In: Candia Carnevali, M.D. \& Bonasoro, F. (Eds.), Echinoderm Research 1998, Balkema, Rotterdam, pp. 93-102.

Materna, S.C. \& Davidson, E.H. (2012) A comprehensive analysis of Delta signaling in pre-gastrular sea urchin embryos. Developmental Biology, 364 (1), 77-87. https://doi.org/10.1016/j.ydbio.2012.01.017

Morise, H., Shimomura, O., Johnson, F.H. \& Winant, J. (1974) Intermolecular energy transfer in the bioluminescent system of Aequorea. Biochemistry, 13, 2656-2662. https://doi.org/10.1021/bi00709a028

Nakamura, S., Mikamori, M., Hiramatsu, M., Eura, S., Takamoto, H. \& Watanabe, M. (2001) Spectacular fluorescence emission in sea urchin larvae. Zoological Science, 18, 807-810. https://doi.org/10.2108/zsj.18.807

Ohguro, Y., Takata, H. \& Kominami, T. (2011) Involvement of Delta and Nodal signals in the specification process of five types of secondary mesenchyme cells in embryo of the sea urchin, Hemicentrotus pulcherrimus. Development, Growth \& Differentiation, 53, 110-123. https://doi.org/10.1111/j.1440-169X.2010.01233.x

Osanai, K. (1969) Behavior of pigment granules during early development in the eggs of a sea urchin, Temnopleurus hardwickii. Annual Report of the Faculty of Education, University of Iwate, 29, 35-38.

Shimomura, O. (1979) Structure of the chromophore of Aequorea green fluorescent protein. FEBS Letters, 104, $220-222$. https://doi.org/10.1016/0014-5793(79)80818-2

Sweet, H.C., Gehring, M. \& Ettensohn, C.A. (2002) LvDelta is a mesoderm-inducting signal in the sea urchin embryo and can endow blastomeres with organizer-like properties. Development, 129, 1945-1955. 
Takata, H. \& Kominami, T. (2004) Behavior of pigment cells closely correlates the manner of gastrulation in sea urchin embryos. Zoological Science, 21, 1025-1035.

https://doi.org/10.2108/zsj.21.1025

Takata, H. \& Kominami, T. (2011) Novel population of embryonic secondary mesenchyme cells in the keyhole sand dollar Astriclypeus manni. Development, Growth \& Differentiation, 53, 625-638. https://doi.org/10.1111/j.1440-169X.2011.01278.x

Ubisch, L.v. (1959) Die Entwicklung von Genocidaris maculata und Sphaerechinus granularis, sowie Bastarde und Merogone von Genocidaris. Pubblica uno studio della stazione Zoologica Anton Dohrn di Napoli, 31, 159-208.

Wray, G.A., Kitazawa, C. \& Miner, B. (2004) Culture of echinoderm larvae through metamorphosis. Chapter 4. Methods in Cell Biology, 74. Elsevier, Amsterdam, pp. 75-86.

https://doi.org/10.1016/S0091-679X(04)74004-2 